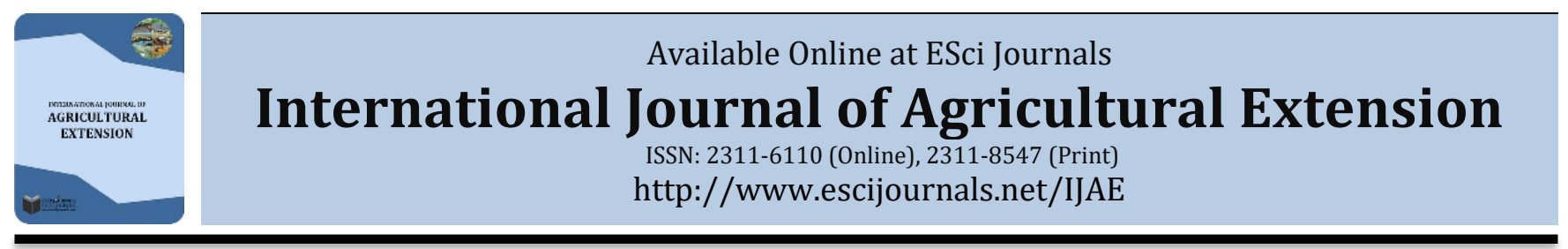

\title{
LEADERSHIP MECHANISMS ASSOCIATED WITH PERFORMANCE OF COFFEE INNOVATION PLATFORMS IN UGANDA
}

\author{
a,bDamalie B. Magala*, aMargaret N. Mangheni, aRichard Miiro \\ ${ }^{a}$ Department of Extension and Innovation Studies, College of Agricultural and Environmental Sciences, Makerere \\ University, Kampala, Uganda. \\ ${ }^{b}$ Mukono Zonal Agricultural Research and Development Institute, P.O. Box 164, Mukono, Uganda.
}

\section{A B S T R A C T}

The demand for diffusion of agricultural technologies led to integration of innovation systems thinking in the agriculture sector as a pathway for delivery of agricultural extension services. However, like other multi-stakeholder organizations, the coffee innovation platforms of Uganda observed persistent challenges of commitment and poor coordination between actors. The reasons why coffee innovation platforms continue to face such challenges are not clearly known; hence the need to explore their underlying leadership issues. This study therefore sought to explain how leadership mechanisms enabled the actors in coffee innovation platforms to achieve their expectations. Data was collected through key informant interviews with 26 actors of the coffee steering committees; three focus group discussions of 19 participants and document review. Analysis was done using content and thematic analysis. The study found that selection of leaders, rules of engagement, incentives, organizational structures, personal attributes and distributed roles are critical but missing leadership facets which require due attention of the innovation intermediaries to build and sustain interactions and relationships in the IPs. The study found that selection of leaders, rules of engagement, incentives, organizational structures, personal attributes and distributed roles were critical leadership The absence of a clear and structured selection criteria and capacity building plan of leaders compromised the diversity of the IP leadership which ultimately affected their performance. To enhance collaborative leadership for better platform performance, this study recommends a clear and structured leadership development model to identify contextual potential leaders and their leadership needs, draw a capacity development plan and develop organizational support mechanisms within a local context.

Keywords: Leaders, mechanisms, innovation platforms, Uganda.

\section{INTRODUCTION}

Leadership is an enabling function in complex adaptive systems to deal with tensions of policy, administration, bureaucracy and innovation. Identification of leadership needs is key to enable actors in given system to experiment, innovate, and respond to realities to achieve the desired purpose (Elking, 2015). Leadership development is therefore a critical and strategic process for improving personal capacities and organizational performance in a competitive business environment (Amagoh, 2009; Leskiw \& Singh, 2007). The process necessitates appropriate mechanisms and systems at all

* Corresponding Author:

Email: dbmagala@gmail.com

(C) 2018 ESci Journals Publishing. All rights reserved. leadership levels. Belinskaja \& Pauliene (2012) defined leadership development as growth of collective individual capacities to direct, align and commit others through interactions. This study defines leadership mechanisms as processes of how leaders are instituted and exercise their powers to achieve platform expectations. Scholarly work by Dror et al. (2016) in India and Kilelu et al. (2013) observed that leadership mechanisms for planning, funding and reflexive monitoring contribute to the survival and performance of innovation platforms since they enhance innovation and continuous adaptation to emerging issues.

Innovation platforms (IPs) as multi-stakeholder processes are recognized as dynamic, distributed networks and governing mechanisms where diverse 
actors with divergent interests and concerns make decisions to improve performance of for example their agricultural value chain (Brouwer et al., 2015; Cullen et al., 2014). The IPs are recognized as approaches for enhancing interactions and linkages among actors to stimulate agricultural innovation (Nederlof et al., 2011; Mayanja et al., 2012). The success of IPs depends on actors' ability to identify a common goal; create trust among potential partners; foster emerging networks, strengthen existing ones and develop innovation capabilities (World Bank, 2012). Performance of IPs is assessed based on their role in technology development, resource mobilization and knowledge management (Daane et al., 2009) or their outputs and outcomes like number of meetings convened, technologies provided, linkages created among actors and participation in joint activities (Nederlof et al., 2011).

In Sub-Saharan Africa (SSA), innovation platforms played a role in enhancing collective action, shared responsibilities and resilience to complex situations (Dror et al., 2016; Tucker et al., 2014). In Uganda, IP approach is recognized as a novel extension service delivery model that stimulates development of agricultural enterprises including coffee (MAAIF, 2010). Coffee is one of the priority enterprises under the National Development Plan contributing 20\% of the national export earnings and supports 3.5 million livelihoods, 39\% are small holder farmers (UCDA, 2012). Robusta coffee accounts for $85 \%$ of $211,872 \mathrm{MT}$ of coffee exports on the international market (UBOS, 2015). Over $69 \%, 13 \%, 10 \%$ of Robusta coffee is produced in central, eastern and south-western regions of the country respectively (UBOS, 2010).

In the public domain, the services to the coffee subsector are segmented among Uganda Coffee Development Authority (UCDA) for regulation, National Agriculture Research Organisation (NARO) for research and Directorate of Agricultural Extension Services (DAES) through local government production departments for extension services. All the three institutions are under the Ministry of Agriculture, Animal Industry and Fisheries (MAAIF, 2013). However, there are weak institutional linkages among the organisations which lead to inefficiencies in the agricultural extension system MAAIF, 2013).

The decentralization policy, legalized by the Local Government Act of 1997, led to devolution of powers and responsibilities from central to local levels.
Consequently, provision of agricultural extension services continues to be a decentralized function for better service delivery to the poor (MAAIF, 2016). The institutional and policy reforms led to the collapse of cooperatives and parastatal bodies like coffee marketing board which adversely affected coffee production and marketing.

In order to revitalize Uganda's coffee sub-sector, Café Africa a Swiss company and a non-profit organization in collaboration with Uganda Coffee Development Authority (UCDA) launched a national campaign in 2008 to improve coffee production and marketing in Uganda. Establishment of the IPs was one of the strategies to address the institutional challenges and thus expected to strengthen the interactions between the different actors and stakeholders in the coffee sub-sector. To ensure that IP activities were directed towards the achievement of the national campaign goal, a national steering committee composed of 13 agencies including government bodies, private sector and development partners was established. Café Africa as a member of the national steering committee was assigned the responsibility of overseeing the formation of the IPs and their operations.

A total of twenty district level IPs were formed by the end of 2008. Each district IP had a structure referred to as coffee steering committee composed of an elected chairperson, a secretary a treasurer and committee members. The objectives of the platforms were to promote the adoption of improved coffee varieties and recommended agronomic practices, re-introduce and promote collective activities, strengthen the coffee value chain as well as advocate for increased investment in the sub-sector (Café Africa, 2009). The key activities of IPs included conducting regular meetings, organizing actors to form associations, linking actor associations to government and private agencies and organizing annual district level coffee shows. The IPs were expected to foster knowledge sharing and learning thereby contributing to better functioning and overall performance of the coffee subsector. However, these desired goals are yet to be achieved (MAAIF, 2013).

In this study, the annual district level coffee shows were considered to be a core activity of IPs because they involved leaders and ordinary members of the IPs. Organizing coffee shows was considered suitable for this purpose because it adheres to the core principles of 
innovation systems including having a common goal whose accomplishment requires interdependence of multiple actors. The shows also acted as a forum in which knowledge, skills and networks were enhanced for better performance of the entire coffee value chain in a given district. Therefore success in organizing coffee shows was measured in terms of number coffee show goers, number of exhibitors, linkages with other stakeholders and financial resources raised for the shows as key performance indicators for all the district level IPs (Café Africa, 2013).

Boogaard et al. (2013) and Brower et al. (2015) argued that although there are operational guidelines for facilitating IPs and there are presence of governance systems in the IPs (Cadilhon et al., 2013; Mulema \& Mazur, 2016), they are still challenges of weak relationships and effective adaptive management strategies (Kileu et al., 2013). Specifically with regard to the coffee innovation platforms, Café Africa (2009) observed that they had persistent challenges of commitment and poor coordination between actors. Reasons why Coffee IPs continue to have persistent challenges related to commitment and coordination among actors are not clearly known. Past studies such as Karp, (2015) and Mehrabani \& Mohamad, (2015) have alluded to the need for more scientific research in leadership development in order to understand how such challenges related to commitment and coordination arise and how they can be addressed. Although the challenges faced by IPs and the options available to deal with them are shaped by the context, only about $16 \%$ of the scholarly leadership studies have emphasized context as a critical factor for explaining leadership dynamics in complex systems (Porter \& McLaughlin, 2006: Hernandez et al., 2011).This study therefore sought to explain how leadership mechanisms in coffee innovation platforms in Uganda enable the actors to achieve their expectations.

Analytical Framework: This study used the Complexity Leadership Theory (CLT) to understand how leadership mechanisms in the Coffee IPs of Uganda affected their performance. Uhl-Bien et al. (2007) noted that CLT framework describes leadership as an interactive and dynamic process that enables learning, creativity and adaptability in a complex adaptive systems. Within the CLT framework, Lichtenstein et al. (2006), Uhl-Bien et al. (2007), Uhl-Bien \& Arena (2016) identified three broad types of leadership namely; administrative or operational leadership; adaptive or entrepreneurial leadership and enabling leadership. Administrative or operational leadership is based on traditional and hierarchical systems for efficient execution of tasks and adaptive or entrepreneurial leadership is seen as the source of novel ideas for learning and creativity.

Enabling leadership on the other hand creates context and conditions (adaptive spaces) that enable networked interactions to foster generation and linking up of novel ideas, innovation and learning in a system. A number of studies such as Porter \& McLaughlin, (2006) and Hernandez et al., (2011) have pointed out context as a critical factor for explaining leadership dynamics in complex systems. Nooteboom \& Termeer, (2013) argued that within complex systems it is difficult to attribute change to individual leaders. They suggest that leadership acts emerge in different networks each at their own level. In order to explain the performance of the innovation systems, this study focused on the context within and outside the coffee platforms as a practical example of innovation systems. Therefore within the CLT, this study adopted the two key tenets of the enabling leadership; that is the context and conditions within the enabling leadership perspective because the performance of multi-stakeholder innovation platforms (MSIPs) is influenced by both intrinsic and extrinsic factors. The intrinsic factors include the internal processes, structures, rules, regulations, incentives and sanctions at play within the MSIPs. The extrinsic factors on the other hand include contextual issues such as external policy, availability of external funding and market forces that have a bearing on the operations of the MSIPs.

Objectives: Specifically the study intended to;

- analyse the processes used in selecting coffee IP leaders and their influence on the performance of the IPs - identify whether and how the structures enabled the leaders to achieve the platform expectations

- explore how rules, incentives and sanctions available to leaders in the process of exercising their powers

- examine how the leadership roles influenced engagement of other stakeholders to achieve their expectations.

\section{METHODOLOGY}

In order to understand the leadership mechanisms the study used the constructivist paradigm basing on individual perspectives and experiences of diverse 
actors involved in the process (Baxter \& Jack, 2008). The constructivist paradigm was considered appropriate for this study because leadership mechanisms and their influence on performance are context specific. A qualitative multiple case study research design (Yin, 2003) was appropriate because it enabled an in-depth inquiry into how the innovation platforms were managed and why they were operating the way they do within their context. The study was conducted in Luwero, Rakai and Ntungamo districts as multiple cases; because they represented different contexts and this therefore enhanced the external validity of the findings. The study sites were purposively selected because of their existence and experience of organizing and implementing coffee shows, therefore the coffee IPs actors provided the data necessary for the study. The sites were also selected because these are among the twenty districts where Uganda Coffee Development Authority (UCDA) and Café Africa intensively promoted coffee campaigns. The study sample was purposively selected from the current lists of the members of the district steering committees. Lists from the three districts were aggregated to form the total sampling frame of 57 leaders. From this sampling frame, 21 key informants were selected and interviewed using an interview guide based on the following criteria; (i) regular involvement in the platform activities and (ii) knowledge of organization of the coffee shows. Table 1 below shows the contribution of each of the four districts to the sampling frame and actual sample.

Table 1. Respondents for the key informant interviews by District and gender.

\begin{tabular}{lcccc}
\hline District & \multicolumn{2}{c}{ Total number of IP leaders/members listed } & Number of IP leaders/members sampled \\
\cline { 2 - 5 } & Males & Females & Males & Females \\
\hline Luwero & 13 & 3 & 5 & 2 \\
Rakai & 16 & 4 & 6 & 1 \\
Ntungamo & 6 & 5 & 5 & 2 \\
\hline Total & 45 & 12 & 15 & 5
\end{tabular}

Focus group discussions (FGDs) were conducted to collect information on how the coffee shows were organized and conducted because organizing and conducting such shows was a collective activity. Lists of all 43 IP leaders and members that participated in the process of organizing and conducting coffee shows were obtained to form the sampling frame for three districts in the previous year (2014); the reference period. A total of 19 respondents were identified based on information from IP chairpersons and review of minutes of preparatory meetings for the coffee shows. Data were collected between November 2014 and March 2015. To generate empirical evidence, the study focused on the descriptive accounts of personal and collective leadership situations and experiences using a FGD check list. Specific data were collected on the selection of IP leaders, structures and roles of the coffee IP committees, expected outputs the coffee shows, roles and tasks of the leader strategies and methods used by the actors.
Secondary data in form of IP committee reports, Café Africa coffee show reports and the coffee show manual of 2013 were used to triangulate and corroborate primary data from key informant interviews and focus group discussions.

Data were analyzed by content and thematic analysis using the five step model by Braun \& Clarke (2006) as follows; (1) conducting the interviews and transcribing the data (2) familiarizing oneself with the data (3) generating initial codes (4) searching for and reviewing themes and (5) defining and naming themes. Field notes and recorded interviews were translated and transcribed from local dialects (Luganda and Runyankole) to English. Codes were derived using the inductive approach as suggested by Merrian (2009) by attaching meaning to individual narratives basing on the researcher objectives. Through this process, related coded were aggregated into broader themes as shown in the Table 2. 
Table 2. Thematic and axial categories generated.

\begin{tabular}{ll}
\hline Thematic categories & Axial codes \\
\hline \multirow{2}{*}{ Identification and selection of leaders } & 1. Actors involved \\
& 2. Promoters of IPs \\
& 3. Methods of identification \\
Leadership structures as enablers & 1. National steering committee \\
& 2. NSC secretariat \\
Leadership experiences, attributes and roles & 3. District steering committees \\
& 1. Actors involved \\
& 2.Performed tasks \\
Outputs of the coffee shows & 3. Methods and strategies used \\
& 4. Implementation process \\
& 1. No of show goers attended \\
& 2. No. of exhibitors by category \\
& 3. Linkages to other stakeholders \\
& 4. Funds mobilized \\
\hline
\end{tabular}

\section{RESULTS AND DISCUSSION}

Measures of coffee IP performance: Café Africa as the promoter of coffee platforms considered organizing and conducting annual coffee shows as a key deliverable for each of the district coffee platform leadership because it involved performance of these different roles. Café Africa only provided each district with generic guidelines and seven million Uganda shillings (equivalent to 2000 USD) per year to organize and conduct the annual coffee shows. The district coffee platform leadership was in turn expected to plan for the annual coffee shows, network with other actors and stakeholders in the coffee sector so as to mobilize them to participate and contribute additional resources for the coffee shows. The district coffee platform leadership was expected to raise $50 \%$ of the total funds as locally generated resources. They were subsequently expected to organize the shows and thereafter assess and report about their performance with regard to their set targets. Receipt of financial support from Café Africa for the coffee shows was dependent on the performance against the set targets of the previous year. Specifically, this study compared the target and actual amount of external funds raised for coffee shows, number of coffee show goers and exhibitors in 2014 as measures of IP performance (Table 3).

Table 3: Measures of performance of coffees shows in 2014 by district.

\begin{tabular}{lccccccc}
\hline Name of coffee IP & $\begin{array}{c}\text { Dates of the coffee } \\
\text { shows (2014) }\end{array}$ & $\begin{array}{c}\text { External funds mobilized } \\
\text { (ushs.000) }\end{array}$ & $\begin{array}{c}\text { Number of coffee show } \\
\text { goers }\end{array}$ & \multicolumn{2}{c}{$\begin{array}{c}\text { Number of } \\
\text { exhibitors }\end{array}$} \\
\cline { 3 - 7 } & & Target & Actual & Target & Actual & Target & Actual \\
\hline Luwero & 12th Sept & 3,500 & 1,500 & 1,000 & 700 & 10 & 16 \\
Ntungamo & 22nd Aug & 3,500 & 9,000 & 1,000 & 825 & 10 & 9 \\
Rakai & 12th Aug & 3,500 & 3,200 & 1,000 & 728 & 10 & 31 \\
\hline
\end{tabular}

Source: District Coffee IP reports, (2014).

Processes used in selecting coffee IP leaders and their influence on IP performance: This study examined the underlying reasons for the composition of IP leadership and the process of establishing such leadership in each of the three districts of focus. Across all the three districts results revealed that selection of leaders was done during the inception meetings as one of the initial activities of IP. Each of the District IP was expected to have a steering committee composed of 1416 people drawn from different actor categories as prescribed in the guidelines from Café Africa. The process of electing the interim steering committees for each district IP was guided by officials from Café Africa. The process involved organizing participants into actor specific sub-groups. Each sub-group composed of members belonging to the same actor category (e.g. 
farmers) then identified representative(s) to the district steering committee. The members of the constituted district steering committee then selected the executive leaders including chairperson, secretary, treasurer and committee members. The guidelines indicated that each category of actors was expected to have at least two representatives on the steering committee. This precondition of having up to two persons from each category compromised the representativeness of the steering committee. For instance, actors such as farmers who are many and are spread across the entire district were underrepresented on the committee. Underrepresentation of some actor categories compromised flow of information between the steering committee and the actors and mobilization of show goers. Table 4 shows that for all the three IPs, farmers had three representatives on the committee Additionally, other actor categories including processors, traders, input dealers, district leaders and financial institutions among others had only one representative on the committee instead of the recommended two.

Table 4. Composition of district steering committees by category.

\begin{tabular}{lcccc}
\hline Actor Category & Luwero & Rakai & Ntungamo & Total \\
\hline Farmers & 3 & 3 & 3 & 9 \\
Extension agents & 2 & 2 & 2 & 6 \\
Nursery operators & 2 & 2 & 2 & 6 \\
NGO/CBO's & 2 & 2 & 1 & 5 \\
Processors & 1 & 2 & 1 & 4 \\
Traders & 1 & 1 & 1 & 3 \\
Agro-input dealers & 1 & 1 & 1 & 3 \\
Regional Coordinators & 1 & 1 & 1 & 3 \\
District leaders & 1 & 1 & 1 & 3 \\
Banks/ SACCO's & - & 1 & 1 & 2 \\
Exporters & 1 & & & 1 \\
\hline Total & 15 & 16 & 14 & 45 \\
\hline
\end{tabular}

Source: District Inception reports, 2008.

The respondents attributed the non-adherence to the preconditions mainly to differences in the existing numbers, spatial spread of the actors and their attendance of the meeting during which leaders were selected. Respondents in the focus group discussions and key informant interviews pointed out that some of the actor categories like farmers needed more representation because they were many and wide spread. The farmer representatives involved in the focus group discussions for instance suggested the need for each of the sub-counties to have a farmer representative at the district steering committee for easy flow of information to all the farmers. Other actor categories such as exporters had fewer than the recommended representatives on the steering committee because they were either too few or they were absent in some districts.

The identification and mobilization of actors was done by district agricultural officers who mainly based on their existing contacts of farmers, extension workers and nursery operators. This meant that actor categories that had no regular contacts with the district agricultural officers stood a high risk of being excluded right from the start of the process. The focus group discussions participants and key informants further revealed that the information used to mobilize participants for the meeting was silent about the plan to select leaders and the number of people to be selected from each actor categories. Results indicate the manner in which actors were mobilized also further compromised the actor diversity of the leadership. In addition to issues of compromised diversity of the IP leadership there was no clear selection criteria for potential leaders. Due to absence of clear and written criteria, members were selected based personal friendships, leaders' experience in community development work and local leadership positions. Café Africa assumed that by virtue of their leadership positions as chairpersons, representatives 
and mobilisers, the committee members would contributed to the success of the IPs, but the leaders lacked clear guidance on how innovation platforms operate and how to command compliance and cooperation from the actors. Key informant interviews revealed that IP leaders never had any orientation and guidance about their roles because there was no deliberate plan for job rotation and capacity building. This was exemplified by a key informant from Rakai whose opinion was as follows "... Ever since the platform was formed, leadership has not changed because we were not well prepared. Apart from the time we met the consultant we have never interacted with her again, we were left on our own, struggling on own without being guided on proper direction ..." (Nursery operator, Rakai district 16th December 2014).

Thus, a combination of the absence of the selection criteria, inappropriate timing of the leadership selection process and lack of clear guidance about IPs could have affected the quality of leaders selected and their expectations from their engagement in IP leadership. Indeed, key informant interviews revealed cases of some of the leaders in two of the IPs (Luwero and Bushenyi for instance, for Luwero district, one female key informant noted as follows "...We made a mistake. Some people who joined the platform perceived it as job but not to provide a service; then regarding leadership issues we were misguided..." (Female respondent, Luwero district, 26th November 2014).

As mentioned by Uhl-Bien et al. (2007) in the CLT, the context and intrinsic factors highlighted above regarding the process of selecting leaders for the IPs generally point to likelihoods of having IP leaders that are not clear about their roles and expectations from the IPs. Lack of clarity about roles and expectations translated into limited commitment which in turn led to low mobilization of key actors. These results are consistent with observations from leadership scholars such as McCallum \& O'Connell (2009), Mehrabani \& Mohamad, (2015) and Uhl-Bien \& Arena, (2016) who advocate for the need for capacity building for leaders and clear leadership selection criteria that are linked to the expected roles. These scholars suggest that the selection criteria and capacity building menu of leaders should include several individual and relational abilities like building teams, empathy, listening, creativity and communication skills to guarantee good performance.

Other scholars such as Leskiw \& Singh, (2007) and
Mehrabani \& Mohamad, (2015) recommend that the criteria for selecting leaders should be linked to the prospective roles and context in which they are to be performed. These scholars observe that selecting leaders based on criteria that are linked to their prospective roles helps to identify leadership development needs thereby paving way for customized technical capacity building and mentoring. Assessing and addressing leadership development needs is especially critical given that the idea of IPs and how they were expected to operate was new to most of the actors. Besides, the process for change of leadership was not given due attention which limited the innovative capacity of the IP's yet successful integration of the leadership development strategies into daily organizational practices is a critical success factor to effective leadership development at all levels (Dalaukora, 2010; Mehrabani \& Mohamad, 2015).

How the structures hindered the leaders from achieving the platform expectations: The ideal structure for the coffee IPs was expected to consist of national, district and sub-county committees. The district committees were expected to mobilize lower level actors in their constituencies and establish committees at lower level (Figure 1). Café Africa coffee IP leadership was however structured as national coffee and district steering committees (Figure 2). The national steering committee (NSC) comprised of 19 representatives from researchers, private sector and development partners. The NSC has a chairperson as it's a head, the secretary (Café Africa) in charge of the national secretariat and the rest of the representatives are committee members. To ensure that the activities of the coffee IPs are aligned to the national coffee sector development agenda, the NSC has one representative from Uganda Coffee Development Authority (UCDA).

The main mandate of the NSC is to enhance coordination of all actors in the coffee sector right from the national level to the grassroots. Thus, the NSC lays strategies for mobilizing different coffee actors and revitalizing their interest in the coffee sub sector at all levels (Café Africa, 2013). A key strategy devised by NSC to mobilize and bring together different actors in the coffee sector, was the district level coffee shows. In implementing the coffee shows, the NSC was responsible for determining the themes of the year, designing the layout of the shows, ensuring quality assurance, mobilizing financial resources and 
advocating for stakeholder engagement. Café Africa, as the secretariat of the NSC performed the coordination role and supported the District Coffee Steering Committees (DSC's) in event planning and resource mobilization.

The district steering committee (DSC) composed of 1416 representatives of actors in the coffee sector including local government leaders, extension service providers, nursery operators, agro-input dealers, processors and traders, farmers, farmer organizations, youth and women representatives is in charge of the coffee platform activities at district level. In collaboration with the NSC, the DSC was supposed to mobilize all actors for the development of the sector.

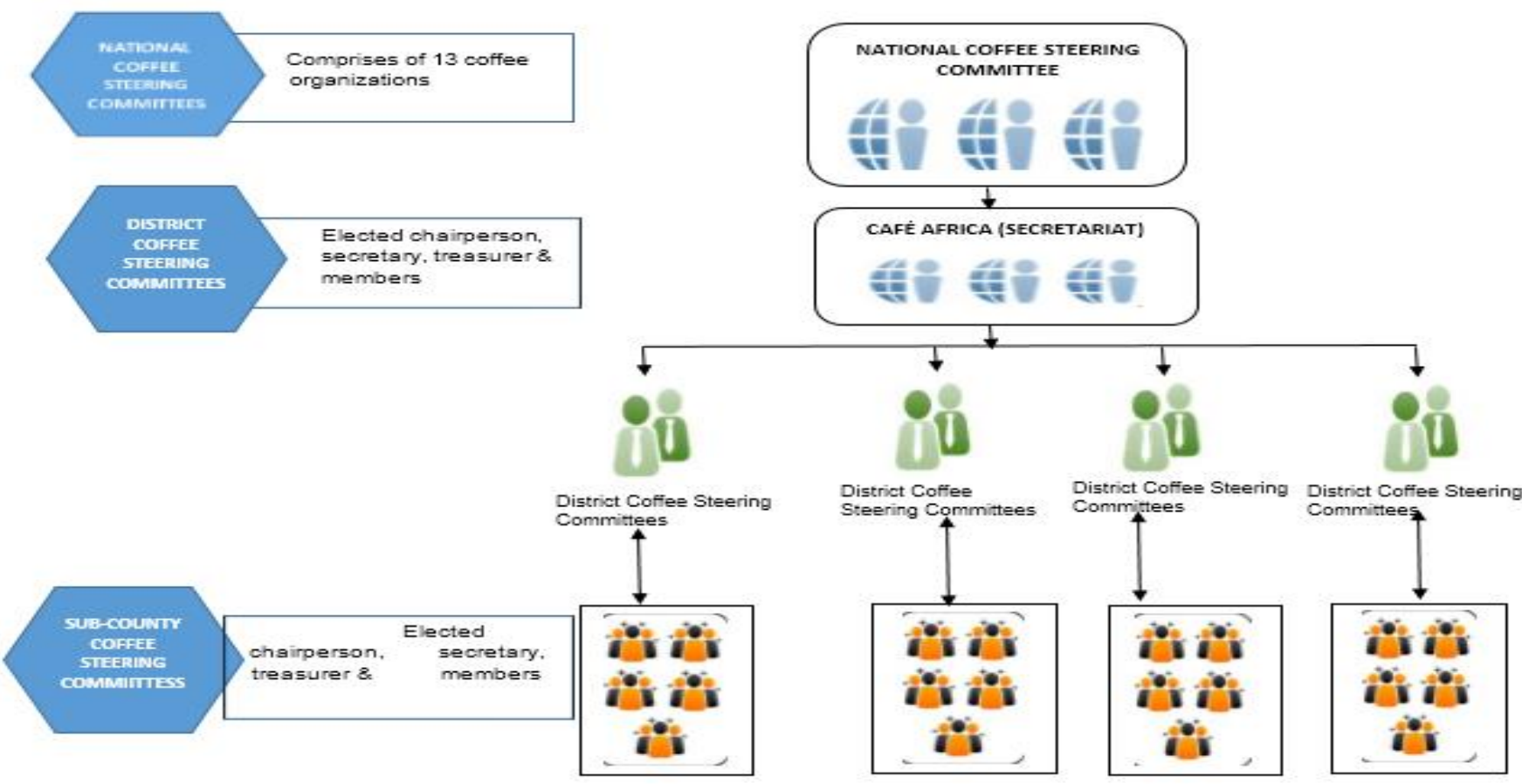

Figure 1. An ideal leadership structure of coffee innovation platforms.
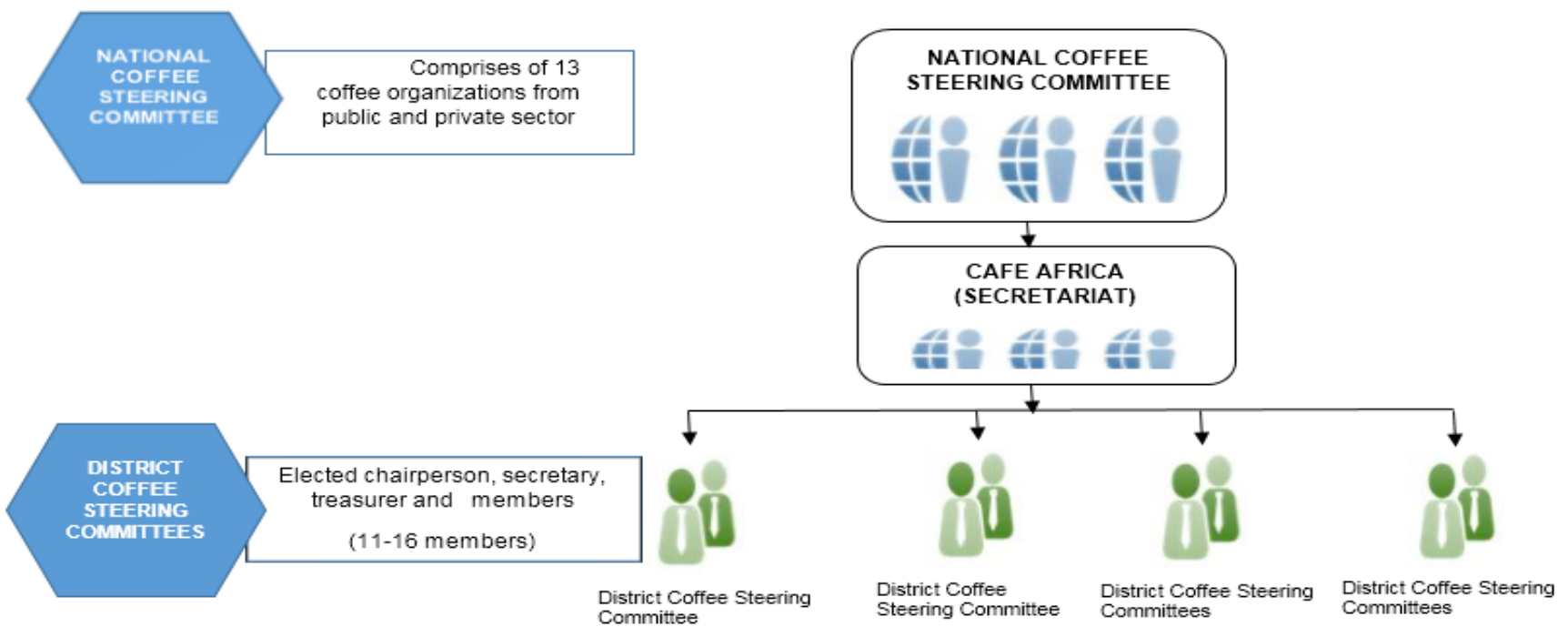

Figure2. Real leadership structures of the coffee innovation platforms. 
Specifically, with regard to the coffee shows, the DSC was mandated to coordinate and manage all operations related to organizing and conducting coffee shows at district level. In line with its mandate, the DSC was expected to perform the roles of strategic action planning which included; technical and process management, fundraising, networking and information sharing, lobbying and advocacy, monitoring and evaluation at district level. Interactions with focus group discussion participants and key informants revealed that the IPs did not have any leadership structures at levels below the district (sub-county, parish and village) where most of the actors they target operate from.

The absence of the structures at sub-county and parish levels severely compromised the flow of information between the existing leadership structures and the targeted actors. They revealed that most of the actors such as farmers, nursery operators, traders and processors targeted by the coffee IPs were operating as individuals not organized in any forms of associations to ease information flow.

In reality therefore, the NSC and DSCs were not operating as expected. At national level, there was a tendency towards Laissez-faire leadership style given that all the rights and power to make decisions were fully given to Café Africa which in turn also transmitted the same to the DSCs. Therefore the rest of the members of the NSC generally took back seats and waited for Café Africa as the secretariat to send reports from the DSCs. Key informant interviews with the representatives on the NSC revealed that other than Café Africa, the rest had limited information about the day to day operations of the coffee IPs.

This resulted into the coffee shows being perceived by district level actors as belonging to Café Africa. Limited involvement of all actor representatives in the activities of the coffee IPs has adverse implications on the performance and sustainability of the NSC and the coffee IPs as a whole. Additionally, reliance of the operations of the NSC on Café Africa poses a risk in terms of their longterm sustainability as observed in other agricultural IPs in Eastern and West Africa. Actor participation and commitment to the IP activities was a challenge without external support (Devaux et al., 2016; Nederlof et al., 2011).

How terms of service influenced performance: As earlier discussed, Café Africa facilitated the actors to form steering committees with no deliberate effort to build their innovative capacities. For instance they were expected to locally raise funds to manage day to day operations and supplement the budget for the coffee shows. The DCSC relied on the chairpersons' competences to mobilize funds.

Table 5. Views of the DSC members on the terms of service and capacity development.

\begin{tabular}{|c|c|c|}
\hline Actors & Terms of service & Capacity building \\
\hline Farmers & $\begin{array}{l}\text { People volunteer, no money for transport, } \\
\text { poor facilitation }\end{array}$ & $\begin{array}{c}\text { Rely on chairman, not trained by Café } \\
\text { Africa }\end{array}$ \\
\hline Extension agents & $\begin{array}{c}\text { Voluntary work, no pay for transport and } \\
\text { lunch }\end{array}$ & $\begin{array}{l}\text { Struggle on our own, no guidance, no } \\
\text { training by Café Africa }\end{array}$ \\
\hline Nursery operators & $\begin{array}{l}\text { No allowance for transport and meals, } \\
\text { personal interests, voluntary work }\end{array}$ & $\begin{array}{c}\text { No skill to manage IPs, not trained by } \\
\text { Café Africa }\end{array}$ \\
\hline Agro-input dealers & No allowance, people sacrifice their time & $\begin{array}{l}\text { Can't manage input dealers, no training } \\
\text { by Café Africa }\end{array}$ \\
\hline
\end{tabular}

Source: Primary data, 2015.

Discussion with all key representatives such as the farmers, extension agents, nursery operators and input dealers understood their work as voluntary. Furthermore, a review of the guidelines for the leadership structures for coffee IPs indicated no form of facilitation and reward system to motivate members to perform their roles. Similarly, no sanctions for unsatisfactory performance were either spelt out. According to the participants in focus group discussion and key informant interviews, the absence of a clear reward system demotivated most of the representatives from dedicating their time and energy to the platform activities. They argued that they needed to be facilitated with allowances, meals and transport to enable them to 
hold meetings and mobilize different actors at the grassroots (Table 5).

Whereas the actor representatives' demands for the material benefits (allowances, meals and transport) was justified given the work they are supposed to do, the financial constraints faced by the district coffee IPs couldn't allow them to meet such demands. Therefore, the DSCs need to be creative and come up with nonmaterial rewarding mechanisms such as public recognition of good performers to motivate leaders. Low performance of the leaders in terms of fund raising for coffee shows and mobilizing diverse actors were compounded by the absence of a clear capacity building procedure for the leaders.This suggestion is supported by Lord and Dinh, (2014), who propose the need for rewards and punishments and succession plans to motivate, inspire and nurture leaders. Availability of external funding as an extrinsic factor influenced the operations and mobilizing of coffee show goers.

How the personal attributes and strategies enable the leaders to execute their roles to achieve IP expectations: In Rakai and Luwero districts, the coffee shows were organized on a rotational basis in the counties. While in Ntungamo coffee shows were perceived as a district event and therefore the venue was Ntungamo Local Government headquarters.

Mobilisation: To organize a successful show, they set up five sub-committees (Figure 3). In Rakai the mobilisation committee headed by the IP district chairperson to mobilize the show goers, exhibitors and raised additional funds. Women mobilization was headed by a female farmer she had access to women groups and her role was to organize members to attend the show, perform drama and share testimonies.

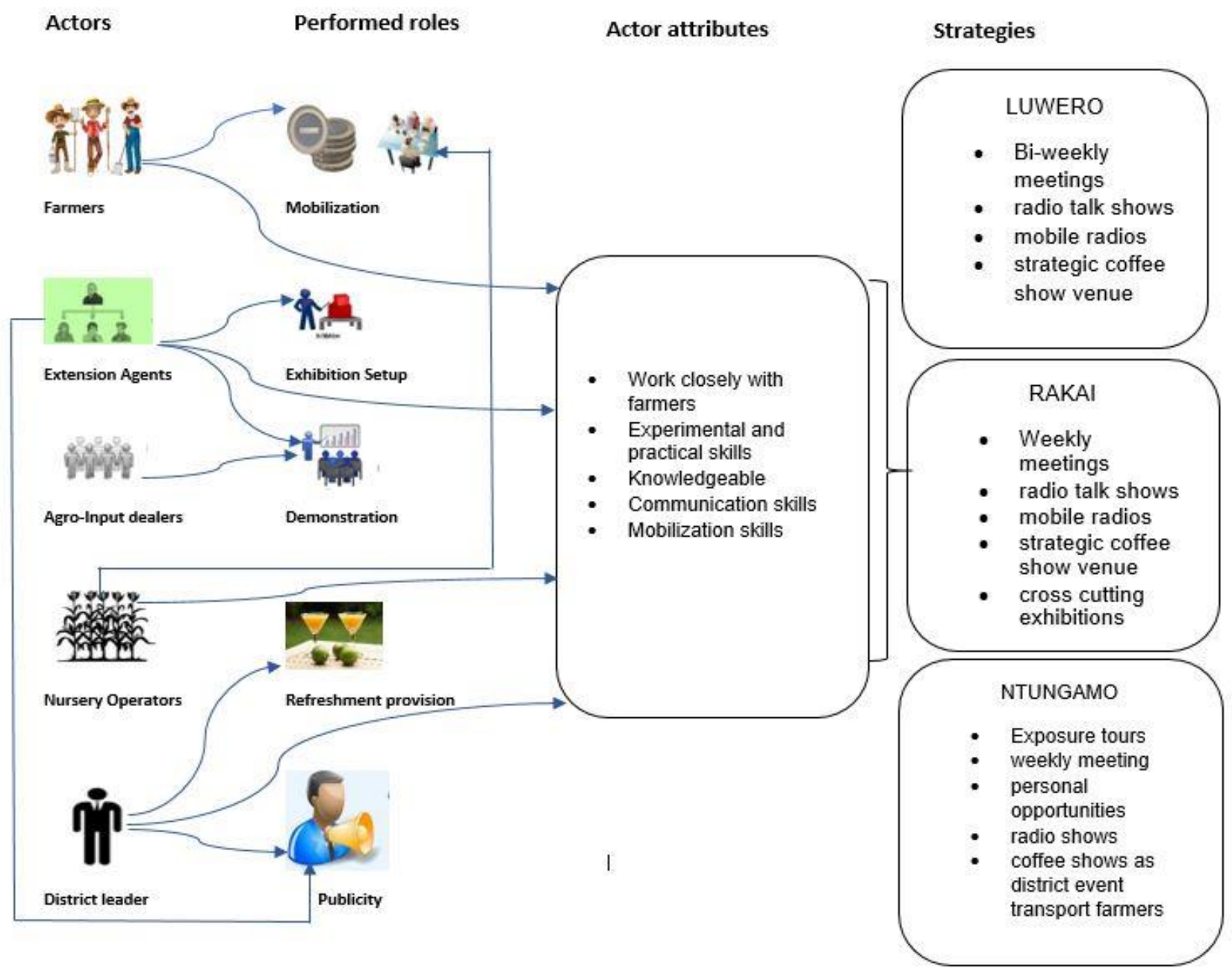

Figure 3. Performed Roles, attributes and strategies of district coffee IP leaders. 
The youth farmer who knew the youth interests mobilized them to participate in the shows as well as perform in the drama events. In Luwero, the mobilisation committee was led by the agro-input dealer and extension agents while in Ntungamo coffee IP leaders used the ASPs to mobilize farmers from all subcounties of the district and with other representatives along the value chain including the farmers, transporters, coffee buyers, processors, as owners of the factories. Representatives of the agro-input dealers mobilized fellow agro-input dealers within the district. While political leaders including the district chairperson, the Resident District Commissioner, Chief Administrative Officer and sub-county chiefs were involved in the mobilization of the show goers. The committee involved primary and secondary schools, hospitals, banks (STANBIC, UGAFORD and SACCOS). This partly explained why Ntungamo attracted more show goers compared to other districts.

Heads of mobilization committee were appointed because they knew most of the people in the coffee subsector. They were good mobilisers and communicators most of the influential persons in the district as suggested during the FGD discussions. The mobilization methods were mainly use of radio talk shows and mobile radios. This is because the channels were most relevant to the main target audience, the farmers. With regard to mobilizing external funds in Table 3, Ntungamo district coffee IP generated the highest amount and this was even higher than what they had expected. The other district coffee IPs performed below their targets with regard to the amounts of external funds mobilized. The good performance of Ntungamo coffee IP with regard to mobilizing external funds is attributed to the leadership of the IPs and the context in which they operated. The lead person of Ntungamo district Coffee IP was also the chairperson of the district local council and Abateganda cooperative society. As the chairperson of the district council, he plays an oversight role over all government agencies within the district and this provided him with the opportunity to regularly interact with all actors in the district. For instance, because of his position, the chairperson of Ntungamo district coffee platform was able to influence the National Agricultural Advisory Services (NAADS) as one of the government agencies in the district to provide some funding for the annual coffee shows.

As a result of the NAADS support, each sub-county in
Ntungamo district contributed 500,000 Uganda shillings (approximately 150US Dollars) to mobilize, facilitate and transport farmers to the annual coffee show. Additionally, being a chairperson of Abateganda Cooperative Society which is one of the most vibrant farmers' organization in the area enabled him to disseminate information about the activities of the IP including mobilizing farmers for the coffee shows (Table 3). A combination of the platform provided by Abateganda cooperative society and financial support from NAADS to mobilize and transport farmers explains why Ntungamo district coffee IP had the highest number of show goers than the other two IPs.

Interactions with focus group discussants and key informants in Ntungamo district revealed that in addition to the fact that their coffee IP chairperson was also a chairperson of the district council and Abateganda cooperative society, he also had strong belief in the ability of the IPs approach to improve the coffee subsector. According to them, their IP chairperson demonstrated his belief in the IP ideology by talking about it in the different fora.

The leadership in coffee platforms in Luwero and Rakai districts that did not possess as much as social capital and political influence as the one in Ntungamo did not perform well in terms of resource mobilization and show attendance. However, in Luwero and Rakai districts, other contextual factors especially the high numbers of other coffee value chain actors within and or near the districts due to their proximity to Uganda's capital city explains why they performed well in terms of attracting more exhibitors for the coffee shows (Table $3)$.

Exhibition set-up and crop demonstrations: In all districts, exhibitions sub- committees were headed by experienced extension agents and nursery operators who had attended many shows and exhibitions and therefore had experience in show organization. The job of this sub-committee was to verify the number of stalls, the type of stalls, organize the tents, tables and stalls according to the value chain. Members of this sub-committee were described as "veterans" with expertise and experience of working with farmers, projects and thus knowledgeable in best practices and methods of coffee production. Respondents recognized the members who held legitimate positions, committed and influential so they were able to acquire resources in form of information materials, funds and 
networks as confirmed by one respondent who said that "...The secretary and nursery operator representative are elders, they accountable and knowledgeable. They are interested and know what to do..." (Extension agent, Rakai district, 16th December 2014). “...Mr. B is an extension worker and chairman of nursery operators; he is transparent and attends most of the agricultural shows in Jinja and Pewosa so he has the experience of organizing shows..." (FGD, Rakai, 15th March 2015).

Publicity and promotion: In Rakai, the Chairperson as the farmers' representative was charged with publicity while Luwero relied on extension agents. In Ntungamo, the district NAADS coordinator headed the publicity committee and promotion materials ( $\mathrm{T}$-shirts and banners) for enhancing awareness about the coffee shows. The coordinator also used his position to raise funds for transporting and feeding farmers from eight sub-counties of the district. In Rakai, the sub-committee for refreshments was headed by the farmer, women and men extension agents in Luwero and nursery operator in Ntungamo. The members of this sub-committee had adequate experience in event and workshop management and had contacts with the appropriate service providers. The phenomena observed in the coffee IPs thus demonstrated that leadership processes are characterized by social capital, interpersonal matters, relational aspects and social awareness (Day et al., 2009).

In Rakai and Luwero the committees met weekly for two months and as the days for the show drew nearer they met every two days. While in Ntungamo, the meetings for organization of the shows started three months before the actual show and they sent delegations to other coffee shows in other districts of Mbarara, Kiruhura. Rukungiri and Isingiro to learn and understand how the coffee shows are organized. Radio shows were held with the vice chairperson, NAADS coordinator, DAO, RDC by explaining the importance of coffee innovation platform. In Rakai, their coffee show event was organised on a market day with the objective of attracting a huge crowd that normally frequents the markets, however some people opted to go for the markets instead of attending the coffee events. Health service providers like "safe organic" who were invited to provide treatment to the communities during the shows also attracted more crowds than the coffee show itself. In terms of leadership however, this displayed some creative skills in terms of attracting crowds during market days. Market days are popular events in most rural areas and often regarded as a social as well as an economic activity; therefore to conduct an event on the same day would be a forecasted failure.

The above findings from the three districts allude to fact that the performance of leaders is largely shaped by the context (methods, strategies, financial resources) in which they operate as proposed by the complex leadership theory. This is consistent with Osborn and Marion, (2009) who observed that appropriate leadership is embedded in its context. Cullen-Lester, Maupin \& Carter, (2016), argue that such skill sets enable leaders to be more influential and inspiring when interacting with others. Further, more socially adept leaders are better prepared to gain access to resources through their social connections. This also implies that IP leadership should consistently scan their operating environment to identify and harness any opportunities that may be available and deal with the threats and challenges that may come along.

Proposed Leadership Development Process for Managing Agricultural Innovation Platforms: IPs are dynamic, complex in nature and people centered; thus their operations cannot be managed by one or few actors. In order to achieve their desired outcomes, collaborative leadership is one of the areas that necessitate critical attention. For actors to solve their problems they need to exchange knowledge and experiences and learn from them, which requires mechanisms and systems for continuous communication, coordination and rational decision making. This implies that IP leaders need to have innovative capacities for fostering interactions and relationships among diverse actors in an organized context. The aim is to involve every actor by cultivating relationships with individuals so that they contribute to their common goal through their mutual responsibilities. Agricultural innovation platforms are typical examples of volatile, virtual and complex adaptive systems which require a shift from hierarchical to relational leadership within organizations. Major flaws in the coffee IPs were observed during the identification, nurturing of leaders and establishment of leadership structures which influenced their operational activities and outcomes. To ensure success of the IPs, effective generic leadership development model needs to be place as presented in Figure 4. 


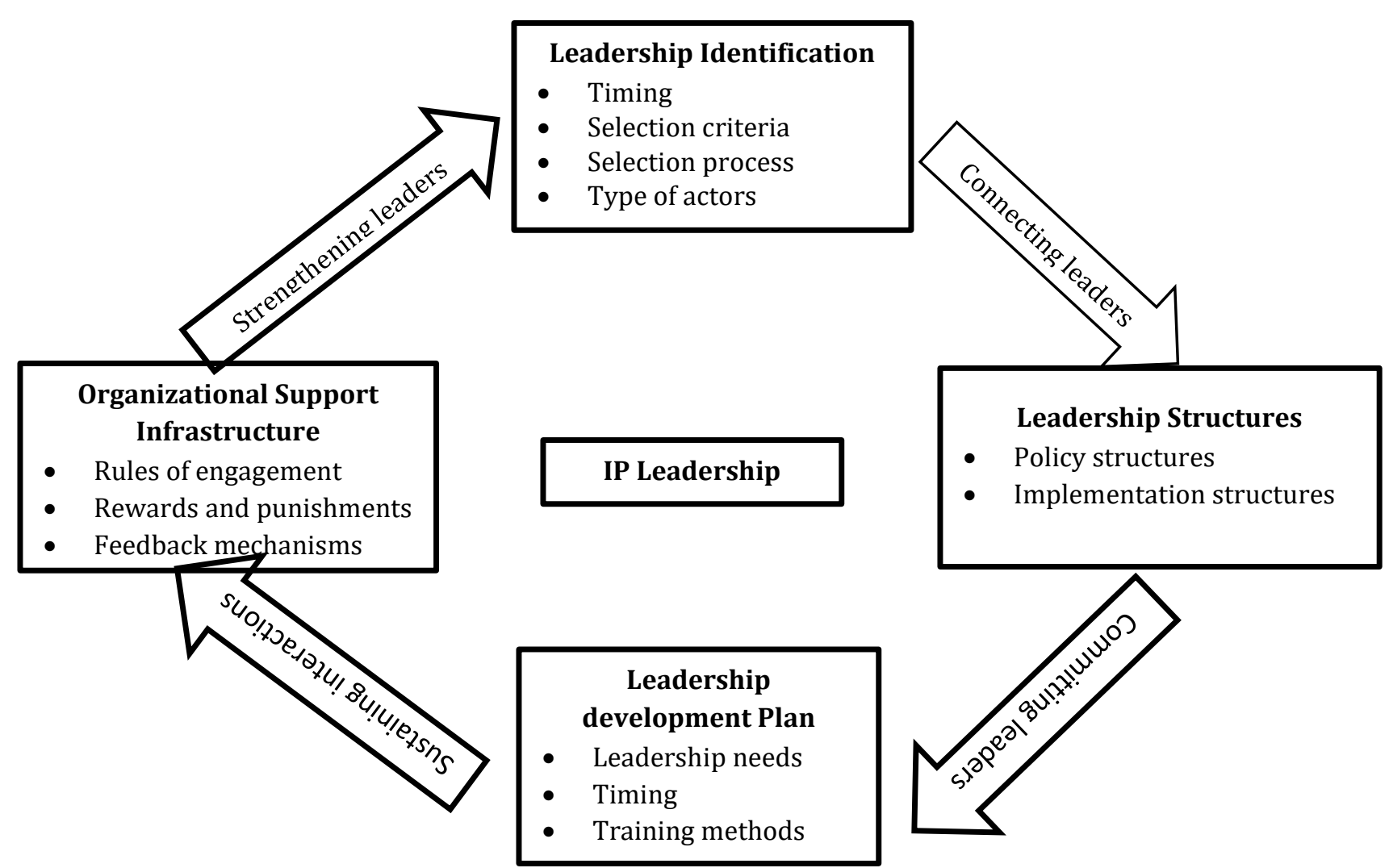

Figure 4. Proposed Leadership Development process.

Identifying potential leaders and leadership needs with constituent members depending on the contextual criteria like positions in the value chain, expertise, experience and attachment to commodity is critical for IP members to engage effectively in leadership roles and processes. In order to nurture and empower leaders, IP facilitators need to draw strategies for enhancing the interpersonal and intrapersonal skills of potential leaders, identify appropriate methods and techniques for imparting the necessary skills and timing for strengthening and sustaining interactions. Developing organizational support mechanisms such as rules of engagement, incentives and rewards, punitive measures, knowledge exchange mechanisms and feedback mechanisms is critical for ensuring sustainability of agricultural innovation platforms.

\section{CONCLUSIONS AND RECOMMENDATIONS}

The study found that the conditions which enable the leaders in collective action to perform include the selection process, rules of engagement, incentives and sanctions organizational structures, personal attributes and distributed roles. These aspects are critical leadership facets which require due attention of the innovation intermediaries to build and sustain interactions and relationships in the IPs.

Since the main outcome of the shows was to enhance actor interactions for better utilization of coffee technologies, the study proposes that high level indicators should be integrated to capture data for instance on the number of linkages established among the actors, proportion of farmers aware of and demanding for exhibited coffee technologies. However, this data can be properly captured where devolution of IP structures occurs at lower levels for better organization of the actors. To enhance IP performance, this study proposes a clear and structured leadership development process to identify contextual potential leaders and their leadership needs, draw a capacity development plan and organizational support mechanisms. Further research is recommended to investigate the sustainability of coffee innovation platforms without external funding.

Conflicts of Interests: As authors of this paper we hereby declare that there are no competing interests in this publication.

Acknowledgment: This research is supported by the 
Agricultural Technology and Agri-business Advisory Services (ATAAS) project funded by World Bank. The authors would like to acknowledge National Agricultural Research Organization (NARO) for the time and support accorded to this research. They would like to extend their appreciation to study participants for their valuable time and insights during the interviews.

\section{REFERENCES}

Amagoh, F. (2009). Leadership development and leadership effectiveness. Management Decision, 47(6), 989-999.

Braun, V., \& Clarke, V. (2006). Using Thematic Analysis in Psychology. Qualitative Research in Psychology, 3 (2), 77-101.

Baxter, P., \& Jack, S. (2008). Qualitative case study methodology: Study design and implementation for novice researchers. The qualitative report, 13(4), 544-559.

Brouwer, H., Woodhill, J., Hemmati, M., Verhoosel, K. \& van Vugt, S. (2015). The MSP Guide: How to Design and Facilitate Multi-Stakeholder Partnerships. Wageningen: Centre of Development Innovation Wageningen University \& Research.

Boogaard, B. K., Schut, M., Klerkx, L., Leeuwis, C., Duncan, A. J., \& Cullen, B. (2013). Critical issues for reflection when designing and implementing research for development in innovation platforms.Belinskaja, L. \& Paulienè, R. (2012). Overview of the Current Leadership Theories: What it Means to Lead? 321-328.

Cadilhon, J. J., Birachi, E. A., Klerkx, L., \& Schut, M. (2013). Innovation platforms to shape national policy.

Café Africa \& UCDA (2009).Terms of Reference for District Coffee Steering Committees (Unpublished).

Café Africa (2013). Coffee Show Manual (Un published) Café Africa Annual Reports 2008-12.

Cullen, K. L., Willburn, P., Chrobot-Mason, D., \& Palus, C. (2014). Networks: How collective leadership really works. Greensboro, NC: Center for Creative Leadership.

Cullen-Lester, K. L., Woehler, M. L., \& Willburn, P. (2016). Network-based leadership development a guiding framework and resources for management educators. Journal of Management Education, 40, 321-358.

Cullen, B., Tucker, J., Snyder, K., Lema, Z. \& Duncan, A., (2014). An analysis of power dynamics within innovation platforms for natural resource management. Innovation and Development 4, 259-275.

Dalakoura, A. (2010). "Differentiating leader and leadership development", Journal of Management Development, 29, (5) $432-441$.

Daane, J., Francis, J., Oliveros, O., \& Bolo, M. (2009). Performance indicators for agricultural innovation systems in the ACP region. Technical Centre for Agriculture (CTA), Wageningen, The Netherlands.Day, D.V., Harrison, M.M. and Halpin, S.M., (2009). An Integrative Approach to Leader Development, Identity and Expertise. New York: Taylor \& Francis Group.

Devaux, A., Torero, M., Donovan, J., \& Horton, D. E. (2016). Innovation for inclusive value-chain development: Successes and challenges. Intl Food Policy Res Inst.

Dror, I., Cadilhon, J. J., Schut, M., Misiko, M., \& Maheshwari, S. (2016). Innovation Platforms for Agricultural Development.

Ebrahimi Mehrabani, S., \& Azmi Mohamad, N. (2015). New approach to leadership skills development (developing a model and measure). Journal of Management Development, 34(7), 821-853

Hernandez, M., Eberly, M. B., Avolio, B. J., \& Johnson, M. D. (2011). The loci and mechanisms of leadership: Exploring a more comprehensive view of leadership theory. The Leadership Quarterly, 22(6), 1165-1185.

Kotlyar, I., Richardson, J., \& Karakowsky, L. (2015). Learning to lead from outsiders: the value of career communities as a source of external peer coaching. Journal of Management Development, 34(10), 1262-1271.

Karp, T. (2015). Studying subtle acts of Leadership, SAGE Publications 9 (1) 3-22.

Kilelu, C. W., Klerkx, L., \& Leeuwis, C. (2013). Unravelling the role of innovation platforms in supporting coevolution of innovation: Contributions and tensions in a smallholder dairy development programme. Agricultural systems, 118, 65-77.

Leskiw, S. L., \& Singh, P. (2007). Leadership development: Learning from best practices. Leadership \& Organization Development Journal, 28(5), 444-464.

Lichtenstein, B. B., Uhl-Bien, M., Marion, R., Seers, A., Orton, J. D., \& Schreiber, C. (2006). Complexity 
leadership theory: An interactive perspective on leading in complex adaptive systems.

Lord, R. G., \& Dinh, J. E. (2014). What have we learned that is critical in understanding leadership perceptions and leader-performance relations? Industrial and Organizational Psychology, 7(2), 158-177.

MAAIF, (2013). The National Coffee Policy. Government of Uganda.

MAAIF (Ministry of Agriculture, Animal Industry and Fisheries). (2016). The National Agricultural Extension Policy, 2016, 48 pages. Kampala: Government of Uganda

Mayanja, S., Akello, B., Horton, D., Kisauzi, D., \& Magala, D. (2012). Value Chain Development in Uganda: Lessons Learned from the Application of the Participatory Market Chain Approach. BANWA Archives (2004-2013), 9(1), 64-96.

Merrian, S. R, (2009). Qualitative Research, A guide to design and Implementation, Jossey-Bass.

Mulema, A. A. (2012). Organization of innovation platforms for Agricultural Research and Development in the Great Lakes Region of Africa.

Mulema, A. A., \& Mazur, R. E. (2016). Motivation and participation in multi-stakeholder innovation platforms in the Great Lakes Region of Africa. Community Development Journal, 51(2), 212-228.

McCallum, S., \& O'Connell, D. (2009). Social capital and leadership development: Building stronger leadership through enhanced relational skills. Leadership \& Organization Development Journal, 30(2), 152-166.

Nooteboom, S.G., \& Termeer, C. J. A.M. (2013). Strategies of complexity leadership in governance systems. International Review of Public Administration, 18(1), 1-16.

Nederlof, S., Wongtschowski, M., van der Lee F. (2011).
Putting heads together. Agricultural innovation platforms in practice. Bulletin 396, KIT Publishers.

Osborn R. N., \& Marion, R., (2009). Contextual leadership, transformational leadership and the performance of international innovation seeking alliances. The Leadership Quarterly 20, 191-206.

Porter, L.W. \& McLaughlin, G.B. (2006). "Leadership and organizational context: like the weather?" Leadership Quarterly, 17, 559-76.

Tucker, J., Schut, M., \& Klerkx, L. (2013). Linking action at different levels through innovation platforms. Innovation Platforms Practice Brief 9. ILRI, Nairobi, Kenya

Uganda Bureau of Statistics, (2015). Statistical Abstract, 2015. Government of Uganda.

UCDA. (2012). Uganda Coffee Development Authority Annual Report.

UCDA. (2014). Uganda National Coffee Strategy 2040 Plan for 2014/15 - 2019/20. Government of Uganda.

Uhl-Bien, M., Marion, R. \& McKelvey, B. (2007). Complexity Leadership Theory: Shifting leadership from the industrial age to the knowledge era. The Leadership Quarterly, 18(4), 298-318.

Uhl-Bien, M., \& Arena, M. (2017). Complexity leadership: Enabling people and organizations for adaptability. Organizational Dynamics.

Weberg, D. R., (2013). Complexity Leadership Theory and Innovation: A new framework for Innovation Leadership. Arizona State University.

World Bank (2012). Agricultural Innovation Systems: an investment sourcebook; Governance of Innovation Systems, ADVANSIS Ltd.

Yin, R. K. (2003). Case study research: Design and methods (3rd Ed.). Thousand Oaks. 